\title{
Exploring the experiences of practice teachers who are not social workers
}

\section{Chris Laycock ${ }^{1}$, Laura Walker ${ }^{2}$ and Laura Heath ${ }^{3}$}

Summary: Professionals without a social work qualification have been involved in the practice teaching of social work students since the days of CCETSW (the former education and training body for social work in the UK). Historically this has always happened more in the voluntary sector. With the advent of the Social Work Degree in England, the 50\% increase in demand for placements in a variety of settings has seen reliance on practice teachers who are not social workers.

This raises some interesting questions about how professionals who are not social workers should be trained and supported in the role of practice teacher.

We will attempt to explore these questions, drawing on responses to a questionnaire sent to a range of practice teachers in a county in northern England as well as feedback obtained from a focus group drawn from respondents to the questionnaire. The participants in the research came from a range of work backgrounds in the voluntary and statutory sectors. The experiences discussed in the research, in the main, relate to the Diploma in Social Work (the former UK qualification) as the degree only started in 2003-2004. We will refer to research participants as Practice Teachers. The key criterion for involvement was that all participants in the study had had sole responsibility for at least one social work student.

Keywords: social work education; voluntary sector; practice teachers; unqualified social workers

1. Service Delivery Manager (until June 2009)

2. Practice Learning Development Co-ordinator

3. Practice Learning Development Worker

Address for Correspondence: The Practice Learning Consortium, c/o SYFM, 55 Queen Street, Sheffield S1 2DX. info@practicelearningconsortium.co.uk

Date of publication: 25th June 2010

33 J. of Practice Teaching \& Learning 9(2) 2009, pp.33-56. DOI: 10.1921/146066910X518094. @ wËb 
Chris Laycock, Laura Walker and Laura Heath

\section{Preface}

This research was carried out and written up during 2006 -2008. The authors would like to acknowledge that although only a short time period has elapsed since the research was conducted there have been significant changes in the field of social work and practice learning prompted by the work of The Social Work Task Force. As such the structure of social work training is currently undergoing considerable reform. This has implications for the content of our research. Some of the terminology and language used in our article is no longer in use, specifically the term Long Arm Practice Teacher is no longer in use and Practice Educator is now referred to in current literature. We refer to the CCETSW/GSCC Practice Teaching Award, which is no longer in existence. Similarly, we also refer to our organisation as The Voluntary Consortium. This has changed to The Practice Learning Consortium.

The work of the Social Work Task Force has put the spotlight on practice learning and in particular the importance of practice learning opportunities (PLOs) which can provide 'statutory social work tasks'. At the time of our research we were working in climate where creativity in developing practice learning opportunities was encouraged and there was an emphasis on service user led organisations becoming involved in practice learning provision. Developing PLOs in a variety of 'non traditional' social work settings was also recommended (Practice Learning Task Force 2006).

The Social Work Task Force has also recommended that in the future Practice Educators are social work qualified. One of our findings was that there was little research regarding Practice Educators who are not social work qualified. There was no research to evidence concerns about Practice Educators who weren't social workers undertaking the role of assessing social work students. Interestingly the Practice Educator Frameworkl does not specify that Practice Educators assessing first placements require a social work qualification In light of this it could be argued that our research has become even more relevant at this time of change where there are contradictions regarding the issue of qualification.

Our research raised questions about the training and support needs of Practice Educators who are not social workers. The issues of teaching social work theory, anti-oppressive practice and maintaining a social work identity are key themes emerging from our research. It is the view of the authors that these themes will remain relevant in terms of the continuing

34 J. of Practice Teaching \& Learning 9(2) 2009, pp.33-56. DOI: 10.1921/146066910X518094. @ wEbb 
Exploring the experiences of practice teachers who are not social workers

professional development of Practice Educators in light of the Task Force recommendations and the fact that the practice learning landscape is ever evolving and changing.

\section{Background and Introduction to the research}

Within the world of social work research little attention has been paid to the experiences of practice teachers who are not social workers. As such, there is no directly comparable research in this area. The nearest that we have is that by Burgess and Phillips (2000), which examines the experiences of the on-site supervisor in practice learning. Literature that discusses issues within interprofessional teaching and assessment, service user and carer led practice learning opportunities, and off site practice assessing can also be considered in relation to our topic.

In the county in Northern England in which this research took place there is well-organised voluntary sector practice learning consortium, which has been instrumental in absorbing practice assessors who are not social workers into the local structures for a number of years. Some of these practice assessors hold the CCETSW/GSCC Practice Teaching Award, a qualification that is no longer awarded but nevertheless it is held in high regard. Our experience locally reflects the view of Davis and Robertson (2002) who consider that the different professional backgrounds have added to the climate of collaboration and learning. However, as Leiba and Leonard (2003) suggest, discussing interprofessional teaching and assessment can create some uncomfortable feelings as well as questions about professional identity and expertise. Armed with these dilemmas we went about the task of exploring the experiences of our sample of practice teachers who are not social workers.

The three main issues we wanted to examine were:

Do practice teachers who are not social workers feel equipped for their role?

What do practice teachers who are not social workers feel are their support needs?

What do practice teachers who are not social workers feel are their training needs?

35 J. of Practice Teaching \& Learning 9(2) 2009, pp.33-56. DOI: 10.1921/146066910X518094. @ w\&b 
We were also interested to explore the 'unique contribution' that professionals felt that they could make to practice learning because of the particular setting or work they were involved in.

This would be done by laying much emphasis on 'practice and the practical relevance of theory' (Department of Health, 2002). The qualifying social work degree in England aimed to produce social workers who would be able to work in new and changing settings such as care trusts and the private and voluntary sectors, as well as in more traditional settings. They must be able to work effectively with other professionals for the benefit of those who rely on social services. In 2002, Jacqui Smith as Minister of State for Health advised that the new degree qualification must prepare social workers for the complex and demanding role that will be required of them.

In England, Wales and Scotland, students are required to complete 200 days of practice (a fifty per cent increase on the Diploma in Social Work) with at least two different service user groups. This has presented a major challenge to placement agencies and universities and has brought with it the need to look beyond 'traditional' practice learning settings. The Practice Learning Task Force (2006) has been instrumental in developing strategies to raise the profile of practice learning throughout the country as well as diversifying the range of opportunities. This has included the development of service user and carer organisations as practice learning opportunities either independently or as Consortia.

We have examples locally of innovative practice learning for students within such agencies as prisons, education, housing, and nurseries. The voluntary and independent sectors are well represented providing approximately 110 placements per year for the two local universities. Nevertheless, much development work has been needed to identify and support new practice learning opportunities within both large high profile charities and smaller charitable organisations as well as other not for profit agencies within the social care field.

When looking at practice teachers who are not social workers it is not enough to examine experiences in the voluntary and independent sectors. Changing employment contexts for all professions has become a sign of the times. However we need to reiterate that at this early point in the degree outside of the voluntary and independent sectors there are only a limited number of practice teachers who are not social workers who fit our criteria. This is likely to change as more practice learning opportunities are established in prisons, education, early years and health settings. Practice learning will inevitably become more reliant on the use of practice teachers

36 J. of Practice Teaching \& Learning 9(2) 2009, pp.33-56. DOI: 10.1921/146066910X518094. @ w\&b 
Exploring the experiences of practice teachers who are not social workers

who are not social workers. It is difficult to see how else the requirements of practice learning will be managed.

In discussing the practice learning requirements of the new degree, Furness and Gilligan (2004, p.467) advise 'students will in future need to be assessed by a qualified social worker'. However they go on to express concern about this since: 'Unless tempered by some provision for the continuing use of existing practice teachers this proposal will inevitably have a direct and significant impact on the placement stock, while the current reality is that there is already a severe shortage of both suitable placements and assessors' .

\section{Literature review}

A literature review on the subject of practice teachers who are not social workers identifies some key themes relevant to our discussion; eligibility to practice teach and assess practice, interprofessional collaboration and learning, and the long arm practice teacher and onsite supervisor model. These themes are discussed below.

In 1989, CCETSW decided to allow people who were not qualified as social workers to become practice teachers, by 2000, Lindsay and Walton (2000) reported that 25 out of 77 agencies indicated that their selection criteria for identifying candidates to undertake the UK Practice Teaching Award took account of this revised CCETSW criteria. It is apparent that participation of candidates from professional backgrounds other than social work has become a feature of many practice teacher programmes (Davis $\&$ Robertson, 2002).

Concerns have been raised that the changes in eligibility to practice teach could result in a dilution in the quality of practice learning. Pryde, cited in Community Care (2000), voiced fears that this was primarily a resource led decision, which would affect the quality of delivery of services to vulnerable people. Lindsay and Walton (2000) raise concerns about a lack of mechanisms for monitoring continuing professional development of practice teachers who are not social workers. However our literature review has revealed no direct investigation into the validity of concerns about the impact of practice teachers who are not social workers on standards of practice learning and ultimate service delivery. In the discussion of our findings later in this article we touch on some experiences and views on

37 J. of Practice Teaching \& Learning 9(2) 2009, pp.33-56. DOI: 10.1921/146066910X518094. @ w\&b 
these issues but would also highlight that these are subjects for future research and exploration.

Today there are differences in guidance about who should be eligible to train as a practice teacher and who can assess students as 'fit to practise'. Thus, the current programme requirements for the Practice Teaching Award state that: "The practice assessor will normally be a qualified social worker or allied professional with at least two years experience of practice teaching, staff supervision, PQ mentoring or teaching/assessment' (TOPPS England/ GSCC, 2002, p.17). However, requirements for the assessment of student practice under the new social work degree state that universities must '(p) rovide for an assessment by an experienced and qualified social worker of the competence and safety of a student to become a social worker' (TOPPS England/GSCC, 2002, p.15).

This implies that a practice teacher who is not a social worker should not carry out assessment, despite such professionals being eligible to undertake the Practice Teaching Award. Within our consortium we feel that an approved practice assessor from an allied profession or not is well placed to manage a first placement if provided with the necessary mentoring and support ${ }^{1}$. This is supported by Lloyd and Worsley (no date) who discuss these changes in the practice learning requirements of the social work degree and possible implications for the role of practice teachers. They report on the idea of different 'levels' of practice teacher, including non social work staff who have undertaken a five day practice teaching training and/or the Practice Teaching Award, concluding that arrangements should be in place for the final assessment of student competence to practise to be made by a qualified social worker.

The guidance concerning eligibility for the CCETSW/GSCC Practice Teaching Award uses the term 'allied professionals' but does not specifically state what is considered to be an allied professional or not. Traditionally, this term may have included established professions involved in work with vulnerable people or in social care roles such as teaching, youth work or nursing or counselling. All of these professions have very careful assessment procedures and policies for academic standards. However, the question about who can be considered an allied professional should be carefully considered, particularly with the growth of new initiatives and within these new and changing professional roles such as a sure start worker, a prison officer, or a learning mentor. In some cases it may be preferable for workers to remain as on site supervisors. Indeed this was the recommendation of Alan Sanders (2007) in his Review of Prison Placements in the Yorks. and Humber areas.

38 J. of Practice Teaching \& Learning 9 (2) 2009, pp.33-56. DOI: 10.1921/146066910X518094. @ wEbb 
Exploring the experiences of practice teachers who are not social workers

It is interesting to note that the guidance assumes that practice teachers who are not social workers will be qualified in a professional discipline, rather than have no professional qualification. In our research two participants did not have any academic qualification and five people did not hold a professional qualification yet had attended various (and often numerous) work based training opportunities. This begs us to ask whether these workers are sufficiently qualified to be able to manage a student's learning experience. As an organisation we have strict criteria and wholesome assessment processes that stand up to scrutiny. We accept that to have this autonomy allows us to interpret what is acceptable but it also ensures that we have a diverse and creative group of both practice assessors and practice learning opportunities. To keep this interprofessional creativity in practice learning we have to ensure that we are ever vigilant that our preparations and training give workers the confidence and expertise around social work identity, roles, values, theory and in the assessment of students as being at the beginning level of practice.

Davis and Robertson (2002, p.4) reporting on interprofessional collaborative activity in Practice Teacher Programmes state that in their view:

one of the most forward-looking aspects of the CCETSW/GSCC Practice Teaching Award has always been the inclusion of people from different professional backgrounds eligible to act as practice teachers for social work students. The experience of nurses, teachers, community and youth workers and others training alongside social workers has been an important factor in developing a climate of interprofessional collaboration in practice teacher training.

The social work degree places emphasis on students learning and achieving competence in interprofessional and collaborative working (Department of Health, 2002). This requirement has prompted a growth in such learning opportunities within universities and on practice learning experiences and raises subsequent issues around how this is assessed. As Whittington (2003, pp.8-9) notes:

The multi-professional dimension poses questions about: the nature of collaborative competence and how it may be achieved and demonstrated; the nature of the professional or interprofessional identity to be developed; and the participation in assessment of social work and non-social work professionals.

39 J. of Practice Teaching \& Learning 9(2) 2009, pp.33-56. DOI: 10.1921/146066910X518094. @ wEbb 
Chris Laycock, Laura Walker and Laura Heath

He continues

Related to the above, there are uncertainties in assessment methodology concerning: requirements and criteria; expected evidence; the standard of performance to be achieved; and an assessment language that is understood by different professions.

For our topic it is useful to note that the literature is consistent in identifying factors that influence the success of interprofessional teaching and assessment; a shared and clear understanding of different professional roles, values, skills, language and potential areas of difference, Whittington (2003), Leiba and Leonard (2003), Davis, Rendell and Simms (2000) and Beale (2001).

The voluntary and independent sectors are increasingly involved in student practice learning. They are offering opportunities for students to learn in very creative settings, which frequently have a multi-disciplinary focus. At the heart is the service-user as discussed by Irvine and Hubbard (2001), Barron (2004) and Doel (2005). A traditional model of involving professionals who are not social workers is through the role of an Onsite Supervisor or Work Based Supervisor, working in conjunction with a Practice Teacher (often off site) who takes responsibility for the teaching and assessment. This 'off site' model is a way of ensuring a practice teacher who is a social worker holds responsibility for final assessment whilst involving another professional who is not necessarily a social worker in the delivery and management of student placements. There are benefits brought by an onsite supervisor role such as an expanded and diverse range of learning opportunities and the input of two professionals with different approaches, knowledge and skill bases in student learning. The day to day involvement of an onsite supervisor can in effect have a significant effect on the practice learning experience through the regular monitoring of a student's direct work as discussed by Burgess and Phillips (2000).

There is a small body of literature that discussed the process and requirements for the offsite practice teacher model to be effective. According to Abram, Hartung and Wernet (2000), the active involvement of student, off site practice teacher and the on-site supervisor in a triad relationship is key to the success of the offsite model. Placements using this arrangement should therefore from the onset establish open and regular communication and clarity around roles and boundaries. Discussing experiences in an interprofessional placement setting, Parker, Hillison and Wilson (2003)

40 J. of Practice Teaching \& Learning 9(2) 2009, pp.33-56. DOI: 10.1921/146066910X518094. @ w\&bb 
Exploring the experiences of practice teachers who are not social workers

identify that the offsite practice teacher's role was key in managing and negotiating different professional perspectives and expectations within the placements.

To summarise, a literature review on the subject of practice teachers who are not social workers identified many references to, and some concerns about this activity taking place. However, the literature does not fully explore key issues such as impact on quality of student learning and the training, development and support needs of such practice teachers. There appears to be a lack of clarity in guidance about eligibility to practice teach and assess practice and apparent inconsistencies with this and the new degree requirements for assessment of student practice. We can draw lessons from literature that explores interprofessional learning in particular the importance of a shared and clear understanding of social work identity and social work's tools in interprofessional teaching and assessment.

Literature that discusses the offsite practice teacher and onsite supervisor model as a traditional way of involving professionals who are not social workers in student practice learning identifies ways to maximise the benefits of this model.

\section{Methods}

We used two methods in our research: a postal questionnaire containing questions of a largely quantitative and qualitative nature together with a focus group. The questionnaire was sent to 39 practice teachers [non social workers] working in voluntary and statutory settings in the identified area. Our research is an illuminative rather than comparative study. As such we did not undertake research with qualified social workers to compare their experiences of practice teaching. However as a training organisation working with social work trained and non social work trained practice assessors we are well placed to comment on this issue. Our observations from group training sessions will be included in the findings.

The authors of this research have a close association with the voluntary sector. This may be reflected in the high number of respondents from the voluntary sector completing our questionnaire. In turn, this may have led to a bias in the overall outcome. However, in undertaking this research we did consult with the Practice Learning Coordinators of the six local authorities within our geographical area. Five co-ordinators provided

41 J. of Practice Teaching \& Learning 9(2) 2009, pp.33-56. DOI: 10.1921/146066910X518094. @ w\&b 
details of their practice teachers who are not social workers. Our research provides information about the experiences of 24 practice teachers who are not social workers, of these 15 work in voluntary sectors and nine in statutory sectors.

Another potential bias arises as one of the authors is herself a practice teacher who is not a social worker. On the one hand, this may give greater insight into the responses and issues raised by the participants as the researchers are operating as 'insiders' [Mc Dermott, 2005]. On the other hand it may also bring an overly optimistic view of the contribution and strengths of practice teachers who are not social workers. The authors have worked to ensure any such biases are recognised and managed in the context of this research.

\section{Questionnaire findings}

The questionnaire was divided into three sections and designed to include a mixture of qualitative and quantitative questions. The purpose of the quantitative questions in sections one and two was to gain a picture of the respondent's work background, employing agency, qualifications, professional experience and level of experience of practice teaching.

The qualitative questions in section two required a more reflective response and asked respondents to consider which aspects of the curriculum they felt most comfortable with; which felt most challenging and what they considered to be their particular, unique contribution to a social work student's learning. (The question regarding the unique contribution was the most commonly not answered suggesting that this may have been perceived as the most challenging area for respondents.) Section three asked respondents to comment on the support they received both inside and outside of their agency. Specifically they were asked to state the nature of support, for example, workload relief, input from colleagues, training and so forth and whether the support had prepared them for their role. Where gaps in support were noted, respondents were asked to identify what their preferred requirements would be. The questions helped to provide a context for interpreting and understanding the practice teachers' own experiences.

42 J. of Practice Teaching \& Learning 9(2) 2009, pp.33-56. DOI: 10.1921/146066910X518094. @ wEbb 
Exploring the experiences of practice teachers who are not social workers

Table 1

Breakdown of 24 respondents and work backgrounds

\begin{tabular}{|l|l|l|}
\hline Statutory Sector & Voluntary sector & Self employed \\
\hline Health 4 & Mental Health 6 & Substance misuse 1 \\
Education 3 & Substance misuse 1 & \\
Social Services 1 & Offending 1 & \\
Youth Offending & Disability 2 & \\
Team 1 & Supported Housing 4 & \\
\hline
\end{tabular}

39 questionnaires were sent to practice teachers from the voluntary and statutory Sectors, 24 completed questionnaires were returned (62\%). Of the 24 respondents 14 were from the Voluntary Sector and nine from statutory agencies, one respondent was self-employed with a background of working in the voluntary sector. This reflected the local picture with regard to the spread of practice teachers who are not social workers.

Table 2

Professional and related qualifications

\begin{tabular}{|l|l|l|}
\hline $\begin{array}{l}\text { Professional } \\
\text { qualification }\end{array}$ & $\begin{array}{l}\text { Qualification in } \\
\text { related discipline }\end{array}$ & $\begin{array}{l}\text { No qualification or } \\
\text { other }\end{array}$ \\
\hline $\begin{array}{l}\text { Teaching 4 } \\
\text { Nursing 5 } \\
\text { NNEB 3 } \\
\text { Occupational } \\
\text { Therapist 1 } \\
\text { Counselling 1 } \\
\text { Youth and } \\
\text { Community Work 1 } \\
\text { Care Management 2 } \\
\text { Housing 1 }\end{array}$ & $\begin{array}{l}\text { Social Sciences 2 } \\
\text { Social and Political } \\
\text { Studies 1 } \\
\text { History Degree 1 }\end{array}$ & $\begin{array}{l}\text { No qualification } \\
\text { stated 2 }\end{array}$ \\
\hline
\end{tabular}

(Note. We have taken the respondents main vocational qualification. Some respondents have more than one professional qualification e.g. counselling and teaching.)

$71 \%$ of respondents had a professional qualification; nursing and

43 J. of Practice Teaching \& Learning 9(2) 2009, pp.33-56. DOI: 10.1921/146066910X518094. @ wEbb 
teaching were most highly represented. $21 \%$ had a degree in a related discipline and two respondents did not have a qualification. In terms of training and experience of practice teaching/assessing 18 respondents (75\%) had completed a five day introduction and five respondents hold the CCETSW/GSCC Practice Teaching Award. The majority of respondents had at least two years experience of practice teaching/ assessing. Some had been undertaking the role for five years or more.

\section{Findings from Questions 7 to 9}

These questions were framed in an open way to allow for unguided responses.

7. Which aspects of the placement curriculum do you feel most comfortable in assessing / teaching?

Why do you feel this is so?

8. Which aspects of the curriculum do you find most challenging?

Why do you feel this is so?

9. What do you feel is your particular contribution to a social work student's learning?

There were varied and multiple responses to Q7, some chose a particular competence and others opted for an area of the practice teaching role e.g. supervision process or values/anti oppressive practice.

Table 3: Areas of the role respondents felt most prepared for

\begin{tabular}{|l|c|}
\hline Area of practice teaching & \% participants who felt prepared \\
\hline Managing the process & 83 \\
\hline Teaching theory & 33 \\
\hline Assessing & 71 \\
\hline Anti Oppressive Practice & 50 \\
\hline Enabling reflection & 75 \\
\hline Dealing with Difficulties & 45 \\
\hline Writing the Report & 45 \\
\hline Other & 8 \\
\hline
\end{tabular}

Not surprisingly respondents chose aspects of practice teaching/

44 J. of Practice Teaching \& Learning 9(2) 2009, pp.33-56. DOI: 10.1921/146066910X518094. @ wEb 
Exploring the experiences of practice teachers who are not social workers

assessing, with which they were most familiar. For example, those who were already established in a supervisory role could transfer those skills. Interestingly one respondent who recognised where their skills were less developed said she:

used the experience of the placement agency, team and on-site supervisor to teach and assess in areas where they have greater knowledge/skills.

Fifty per cent of the respondents considered that they were most comfortable with teaching/assessing values and anti-oppressive practice. They felt this was attributable to the high level of direct work with service users. Where respondents had time to research and prepare exercises to use with students, levels of confidence was higher. This provides strong evidence for ensuring practice teachers have workload relief for preparation and reading.

Fifty per cent of the responses to Q8 raised particular individual challenges including keeping up with paperwork, issues relating to specific students and matching learning opportunities to the curriculum. Two respondents reported that they found nothing challenging. 33\% of respondents cited teaching social work theory as the most challenging and only $50 \%$ felt that they were prepared for teaching aspects of anti-oppressive practice. It is particularly significant and concerning that two fundamental areas should pose a challenge to a considerable number of the participants, although perhaps not surprising. Payne (2005) discusses the general low confidence amongst qualified social workers in integrating theory to practice. This becomes more interesting when looking at our research findings as practice teachers who are not social workers attributed the challenges connected with theory to the fact that they weren't qualified. One respondent stated this specifically:

Because we're not practising social workers and don't work directly with theories or have some way of keeping up to date with academic developments.

The perceived difficulty in working with social work theory raises some questions for further exploration such as: What actually is social work theory? What are the difficulties? How might the difficulties be addressed?

Statements from respondents and indeed from workers in the profession generally promote a notion of theory as something

45 J. of Practice Teaching \& Learning 9(2) 2009, pp.33-56. DOI: 10.1921/146066910X518094. @ w\&b 
unattainable, with an almost enigmatic quality. From our own observations facilitating training with trained social workers and unqualified workers, the anxiety regarding theory is apparent in both groups. Payne (2005) helpfully explains the idea of theory as 'universal' and 'static' are not truisms, nor are they useful. He suggests that theory is 'constructed by worker, client and the context in which it is used'. As such it is reflexive rather than static. Similarly, Shardlow and Nelson (2005) suggest looking at social work as 'a constellation of knowledge and skills, where what is discrete to the social work profession is the coming together of specific knowledge and skills'. Both of these concepts provide a more 'user friendly' perspective and could help to alleviate some of the anxieties held by both social workers and other professionals.

It may be useful for practice teachers to be encouraged to focus on using theories relevant to their setting and not feel pressurised to have a knowledge of each theory relevant to social work - after all this is an unachievable task qualified or not! Placements can be seen to be an opportunity to specialise and explore specific theories/approaches, whilst academic teaching focuses on core theories and models. Social work theory was debated in the focus group. (Further discussion relating to improving working with theory is included in the section relating to the focus group).

In terms of anti-oppressive practice (AOP), questionnaire responses indicated that practice teachers felt that their settings did not provide opportunity for working with AOP when they were situated in predominantly white working class areas. These practice teachers perceived race to be the core issue relating to meeting $\mathrm{AOP}$ requirements. Furthermore, there was evidence to suggest that practice teachers felt that students needed to work with service users experiencing all types of structural oppression to satisfy the AOP criteria.

It is clear that there is a misunderstanding about AOP and how it can be integrated into practice. This raises questions about whether practice teachers have examined and identified their own value base and understanding of structural oppression. It also highlights the need to find a useful and meaningful way of unpicking AOP and making its practical application explicit in our work with students. This issue relates to a previous point about allowing practice teachers the time for researching relevant teaching exercises, for example those devised by Doel and Shardlow (2005). Similarly, practice examples could be

46 J. of Practice Teaching \& Learning 9(2) 2009, pp.33-56. DOI: 10.1921/146066910X518094. @ w\&bb 
explored with practice teachers in training, for example; where a student challenges oppressive practice/statements from others, or accessing a profile of the geographical area and examining local cultures. The responses from this research would suggest that there is a need to promote a wider view amongst our practice teachers who are not social workers in considering AOP and its application.

We asked participants to comment on whether they felt supported in their role teaching/assessing students. In the main (75\%) felt that they accessed support from their colleagues and that a 'good learning culture' and 'positive view of social work' also helped. Only 13\% (three participants) said that they had a reduced workload whilst practice assessing.

Table 4: Internal sources of support cited by respondents

\begin{tabular}{|l|c|}
\hline Internal Sources of Support & \% of respondents citing \\
\hline Support of team & 63 \\
\hline Reduced workload & 13 \\
\hline Supervision & 16 \\
\hline Student valued in wider organisation & 54 \\
\hline Positive view of social work within organisation & 45 \\
\hline Organisational learning culture & 16 \\
\hline Other & 4 \\
\hline None & 4 \\
\hline
\end{tabular}

$62 \%$ said that they received support from outside of their agency, the majority of these participants named the Voluntary Consortium as the provider of training, one-to-one support and workshops.

Some participants gave ideas about how support could be developed including sharing of teaching resources, developing a peer support network, theory updates, reduced workload and regular curriculum refreshers. These ideas would suggest that practice teachers feel that regular group work and sharing of experience and knowledge would increase support networks. This finding fits with the 'collective confidence' that became apparent from the focus group findings. 


\section{Focus group findings}

Twelve people had given responses and raised issues in their questionnaires that we identified as key themes and we felt that it was important to explore these further via a focus group. Of the twelve who were invited six practice teachers agreed to take part in the session. Four were from the voluntary sector and two from the statutory sector. The format for the group was a general discussion around some common themes arising from the questionnaire. This discussion was audiorecorded and transcribed.

The table below identifies each participant according to the service user group that she/he works with, as well as their professional qualification and the number of years qualified.

Table 5

Focus group qualifications

\begin{tabular}{|l|c|c|c|}
\hline Code & Service user group & $\begin{array}{c}\text { Professional } \\
\text { Qualification }\end{array}$ & Years qualified \\
\hline FG1 & Youth Justice & $\begin{array}{c}\text { Youth and comm. } \\
\text { work }\end{array}$ & 22 \\
\hline FG2 & $\begin{array}{c}\text { Children and } \\
\text { families }\end{array}$ & NNEB & 25 \\
\hline FG3 & Mental Health & RGN and RMN & 25 and 23 \\
\hline FG4 & Mental Health & $\begin{array}{c}\text { Occupational } \\
\text { Therapy }\end{array}$ & 23 \\
\hline FG5 & $\begin{array}{c}\text { Children and } \\
\text { Young people }\end{array}$ & None & - \\
\hline FG6 & Mental Health & $\begin{array}{c}\text { Dip in Business } \\
\text { Management }\end{array}$ & 5 \\
\hline
\end{tabular}

There are some interesting differences between the responses from the questionnaires and the views expressed in the focus group. As previously discussed, 33\% of the respondents reported that they felt particularly challenged by teaching theory and $50 \%$ by teaching and assessing anti-oppressive practice. These two themes were not reflected in the focus group findings. In fact the opposite was true. There was a general confidence amongst the group about their abilities in these areas. One of the respondents who had cited integrating theory into practice

48 J. of Practice Teaching \& Learning 9(2) 2009, pp.33-56. DOI: 10.1921/146066910X518094. @ wEb 
Exploring the experiences of practice teachers who are not social workers

and providing opportunities for anti-oppressive practice as the most challenging aspects in her questionnaire response was a member of the focus group and her views (highlighted below) changed quite significantly for the positive during the group discussion. This may be as a result of the process of group dynamics. For example, meeting with other experienced practice teachers may have generated an increased awareness of each group member's own skills and knowledge. Or alternatively peer pressure may have had had an impact; on hearing other group members' contributions respondents may have felt under pressure to agree with others or make similar statements.

All focus group participants were confident about their contributions to social work student training. This may not be surprising as most of the group are experienced practice teachers/assessors. (This level of confidence may also have grown during the course of the group). However, even the practice teacher who has only the experience of one student to reflect on could say:

We were conscious at the outset that we could give the student what she wanted.... The nuts and bolts of work with children. The point at which concerns are picked up and passed to Social Services.

She did however acknowledge that this may have been different if the student had not been a proactive learner.

This same practice teacher was concerned about the agency's ability to provide an AOP framework to the placement but she soon realised that this was the way that the agency worked. Three other participants who felt confident that their agency would provide a strong AOP framework backed up this view. This confidence was particularly strong in respondents from mental health settings. One practice teacher, who is nurse trained, felt that her agency had shaped her values and beliefs towards client centred work. This notion was also highlighted from another respondent in his questionnaire:

The foundations of social work; respect, communication, listening, AOP, nonjudgmental etc can be learned/assessed in any setting even if it is not a purely qualified social work staff team.

This idea has been explored by Leiba and Leonard (2003) who identify the significant identifiable overlap of many professional skills

49 J. of Practice Teaching \& Learning 9(2) 2009, pp.33-56. DOI: 10.1921/146066910X518094. @ wËb 
between different professions within health and social care fields, e.g. mental health social worker, community nurse and so on.

The practice teacher from a Youth Justice setting was a little less certain about a team identity in relation to AOP. Here police officers work side by side with social workers. The practice teacher did not feel confident that these colleagues could manage the role of a practice teacher unless they had specific training in 'What is Social Work?' to help them identify the roles, skills, knowledge and value base of social work.

This belief was echoed by a social work trained freelance practice teacher who has supported the prison placements as an off site arrangement. Although the prison officers have completed the Introductory Course in Practice Assessing it was felt that they required additional training on 'What is Social Work?'.

In relation to theory, the participants in the focus group felt sufficiently confident in their own role to help the student to relate theory to practice. They were unanimous in their belief that:

... social work theory is borrowed from subjects such as sociology and psychology as well as politics and social policy.....there is also the theory coming from user involvement, life story work and narrative therapy that we feel comfortable with.

This belief helped them to understand that social work theory per se was not an exclusive subject and that they were well placed to create a 'spirit of enquiry' within social work students. This belief is in keeping with the ideas of Payne (2005), Shardlow and Nelson (2005) and Low and Weinstein (2000) as discussed in Leiba and Leonard (2003).

All participants in the focus group could describe the different theories that they used as practitioners and for those from the voluntary sector this was reflected in the organisation's culture. The practice teacher from Youth Justice was comfortable with his own understanding and application of social work theory but not with that of the agency as a whole. He described how the service had moved towards 'systems and performance indicators'. It is interesting that this is perceived as a move away from social work; since work dominated by systems and performance indicators increasingly reflects the experience of social workers in statutory social work settings

The low levels of confidence evident in the questionnaires were not replicated in the group discussion. In fact the group members were

50 J. of Practice Teaching \& Learning 9(2) 2009, pp.33-56. DOI: 10.1921/146066910X518094. @ w\&bb 
Exploring the experiences of practice teachers who are not social workers

articulate when discussing social work theory and could identify several theories and models used in their practice.

There was a sense of appreciation of the apprenticeship style of learning within less traditional organisations. For example, one practice teacher from a Children's Centre mentioned:

... on one day the student would sit beside me while I made a case for more money at a meeting with funders and on the next day I could be sitting on the floor with a couple of three year olds playing.

This 'multi-tasking' nature of the work was seen as an important part of learning and understanding about the wider social work picture and 'a sense of reality about the work place'.

Throughout the meeting there was a case being made for the flexibility particularly of the voluntary sector in responding to last minute requests from the universities for placements and in the provision of opportunities for students with specific needs. Participants gave examples of how they and their agencies had been able to offer flexibility and support to students with disabilities, specific health needs and caring responsibilities. We have identified this as a significant aspect of the unique contribution to social work education of such agencies.

The commitment of participants to their role of practice teacher was evident throughout the discussions but there was also an expressed need for more support from the universities with regard to ensuring that agencies are clear about what the student is learning at university. Participants felt that they needed a course handbook, lecture notes and support from a tutor who is aware of the academic work completed before the placement. More joint work with the university/university tutor would also perhaps enhance the ability and confidence of the practice teacher in linking theories and anti-oppressive practice into the placement. Clapton and Daly (2005) discuss how university tutors spend time on placement jointly teaching with practice teachers. They describe how this has 'bridged the gap' between the worlds of theory and practice with tutors gaining insight into practice issues and practice teachers more easily making the necessary links to theory. The ultimate benefit for the student is a greater understanding of the relationship between theory and practice. Such an initiative obviously has resource implications in terms of university staff and practice teachers time. However simple measures such as giving practice teachers access to

51 J. of Practice Teaching \& Learning 9(2) 2009, pp.33-56. DOI: 10.1921/146066910X518094. @ w\&bb 
university online teaching materials could help them stay informed and up-to-date on what students are learning at university.

From the focus group there was also an overwhelming belief that the voluntary sector should be more actively involved in a 'Readiness to Practice Module' to ensure that students are prepared for the very varied opportunities for learning available on placements. Should this come to fruition, a 'joined up' approach to placements would be set in motion from the start.

\section{Key findings and recommendations}

To analyse the findings of our research it is helpful to return to our initial questions:

\footnotetext{
Do practice teachers who are not social workers feel equipped for their role?
What do practice teachers who are not social workers feel are their support needs?
What do practice teachers who are not social workers feel are their training needs?

There is a clear finding that a significant proportion of our participants do not feel adequately prepared for teaching theory and anti-oppressive practice. Critics may say that this is a reason not to use practice teachers who are not social workers. It is our view that we need to recognise the contribution they make and to take these strengths to further motivate, train and support and encourage this valuable resource so that they provide an even more valuable contribution to social work student learning. This presents an interesting challenge to infrastructures in the statutory and voluntary sectors as they prepare for the increasing number of placements required by universities. We need to recognise that training is required throughout the career of a practice teacher. Such training should explore with potential and current practice teachers their knowledge and application of theory, and ways in which social work theory is viewed and even feared.

There is a strong feeling from participants that more integrated working and communication with universities would be useful particularly in

52 J. of Practice Teaching \& Learning 9(2) 2009, pp.33-56. DOI: 10.1921/146066910X518094. @ w\&b 
Exploring the experiences of practice teachers who are not social workers

respect of working with theory. In practical terms this could be enabling practice teachers to use the university libraries and IT systems for sharing and accessing information about the academic curriculum.(At the time of writing one of the local universities has acknowledged this gap in collaborative working and is building a web site that all practice assessors will be able to access.)

Participants in our research also told us that opportunities for peer support would be welcomed on a more regular basis in order to reflect on experiences and maintain confidence in ability. This group model may be an effective forum in which anti-oppressive practice could be explored in depth and understanding of how to work with students calibrated. The exchange of ideas and practice examples may also lead to an increased confidence similar to the process that took place in our focus group.

As respondents attributed their lack of confidence in working with theory and anti-oppressive practice to their status as practice teachers who are not social workers, perhaps it would be prudent to expand current training to include an extra day focusing on 'What is Social Work?' This day could precede the existing five day requirement and could specifically explore the participants' understanding of social work, the values underpinning practice, identity of the profession and the skills and theories used.

A major theme emerging from our research was the creativity and enrichment brought to the practice learning experience and indeed to the profession by the respondents in our research. Fourteen of the respondents spoke of the high level of direct work and the quality of relationships with service users their work offered and therefore a wealth of learning opportunities for students. From the focus group discussion, it is apparent that practice teachers are using a variety of social work methods, which a student could adopt into their 'toolkit'. This creativity coupled with the ability to accommodate students with particular needs would indicate that the value in preparing, training and supporting practice teachers who are not social workers in less traditional social work agencies for their role is one worth pursuing, investing in and building on.

Our research has examined the experiences of practice teachers who do not have social work training. From our observations many of the challenges discussed could also apply to qualified social workers. This said we are aware that the evidence for this is not substantiated and as such this is an area to take forward into another piece of research.

53 J. of Practice Teaching \& Learning 9(2) 2009, pp.33-56. DOI: 10.1921/146066910X518094. @ wËb 
Chris Laycock, Laura Walker and Laura Heath

\section{Summary}

We have listened and learnt from this piece of research and within the voluntary consortium we have tried to integrate some of the needs of practice assessors who are not social workers into the planning of support. A major change has been the introduction of an additional half-day within the practice assessor course for non social workers. This takes place before the main part of the course to prepare and nurture participants. This half-day is facilitated by a specialist practice assessor [part of the research team] and aims to look at 'what is social work'?

The main part of the course has also been revamped to allow for exercises that encourage participants in non-traditional settings to recognise the 'social work' and research opportunities that are already happening in their agencies. We have also introduced group supervision as an additional support to targeted agencies to enhance the social work perspective but at the same time respecting that the agency has overall responsibility for the management of the placement .

A final significant response has been the creation of an annual rolling programme of workshops for Practice Assessors [using the skills within the consortium]. These will cover particular theories and methods as well as curriculum support activities. It is too early as yet to assess the significance of these changes. However, we have an enviable position as a training organisation for social work qualified and non social work qualified assessors from which to make observations. From evaluations so far we have observed that additional training relating to theory results in a 'collective confidence' across both groups. Discussions and reflections have a knock on effect on the whole group in helping to identify unconscious work practices that have theory at the very heart of interactions with service users and other professionals. We hope that this evolving process of continuous professional development will prove to be the catalyst that strengthens this very valuable resource within practice learning across the voluntary and independent sectors as well as in other non-traditional practice settings.

54 J. of Practice Teaching \& Learning 9(2) 2009, pp.33-56. DOI: 10.1921/146066910X518094. @ wEbb 


\section{Note}

1 An approved practice assessor is one who has both completed the 'introduction to practice assessing course' and successfully managed a placement without off site support. All non social work trained workers are supported by off site assessors with their first student. Approvals are granted at the consortium's monitoring and evaluation committee made up of experienced practice assessors.

\section{References}

Abram, F., Hartung, M., and Wernet, S. (2000) The non MSW task supervisor, MSW field instructor, and the practicum student: A triad for high quality field education. Journal of Teaching in Social Work, 20, 1/2, 171-185

Barron, C. (2004) Fair play: Creating a better learning climate for social work students in social care settings. Social Work Education, .23, 1, 26-37

Beale, H. (2001) Teaching Supervising and Learning in the Workplace. accessed 26th September 2006 at www.swap.ac.uk/casestudies/cshbeale.rtf

Burgess, C. and Phillips, R. (2000) On-site supervisors: The unsung partners in the training team?. Journal of Practice Teaching in Health and Social Work, 2, 3, 28-46

Central Council for Education and Training in Social Work (CCETSW) (1989,1991) Improving Standards in Practice Learning: Requirements and Guidance for the approval of Agencies and the Accreditation and Training of Practice Teachers. Paper 26.3. London: CCETSW

Clapton, G. and Daly, M. (2005) Leap over the learning gap. Community Care, 3-9 March

Community Care (2000) Emergency motion hits at non-qualified workers. 7th June

Davis., J. and Rendell, P., and Sims, D. (2000) Practice teaching and learning on an interprofessional course. Journal of Practice Teaching in Health and Social Work, 3, 1, 5-20

Davis, J., and Robertson, J. (2002) Working and Learning Together In Practice Teaching and Learning. London: Interprofessional Practice Teaching Working Group

Department of Health (DoH) (2002) Requirements for Social Work Training. Norwich: TSO

Doel, M. (2005) New Approaches to Practice Learning. Research project

55 J. of Practice Teaching \& Learning 9(2) 2009, pp.33-56. DOI: 10.1921/146066910X518094. @ w\&b 
commissioned by the Practice Learning Task Force as part of a series of publications on Capturing the Learning'

Doel, M. and Shardlow, S. (2005) Modern Social Work Practice: Teaching and learning in practice settings. Farnham: Ashgate

Furness, S. and Gilligan, P. (2004) Fit for purpose: Issues from practice placements, practice teaching and the assessment of students. practice. Social Work Education, 23, 4, 465-479

Irvine, J. and Hubbard, A. (2001) Is good will enough? Practice teaching in the voluntary sector. Journal of Practice Teaching in Health and Social Work, 3, 3, $7-23$

Leiba, T. and Leonard, K. (2003) Interprofessional education: The reality of an interprofessional practice teacher course. Journal of Practice Teaching in Health and Social Work, 4, 3, 14-28

Lindsay, J and Walton, A. (2000) Workforce Planning and the Strategic Deployment of Practice teachers in Approved Agencies in the CCETSW England Regulation in 1999. London: CCETSW

Low, H. and Weinstein, J. (2000 Interprofessional education. in R. Pierce and J. Weinstein (Eds.) Innovative Education and Training for Care Professionals: A providers. guide. London: Jessica Kingsley

Lloyd,. K and Worsley, A. (no date) Role of Practice Assessor / Practice Teacher. accessed $26^{\text {th }}$ September 2006 at www.practicelearning.org.uk

McDermott, F (2005). Researching groupwork: Outsider and insider perspectives. Groupwork, 15, 1, 90-108

Parker, J, Hillison, K., and Wilson, L. (2003) SWiSP: The Social Work Students in Schools Project. Practice, 15, 4, 69-87

Payne, M. (2005) Modern Social Work Theory. Basingstoke: Palgrave

Practice Learning Task Force (2006) Active Participation in Practice Learning

Practice Learning Task Force (2006) Developing Strategies in Practice Learning. Leeds: Practice Learning Task Force

Sanders, A. (2007) South Yorkshire Learning Resource Network Review of Prison Placements. Skills for Care, Yorks. and Humber

Shardlow, S. and Nelson, P. (2005) Introducing Social Work. Lyme Regis: Russell House

TOPSS England and GSCC (2002) Guidance on the Assessment of Practice in the Workplace. London: GSCC

Whittington C (2003) Learning for Collaborative Practice with other Professionals and Agencies: A study to inform development of the Degree in Social Work. (Summary Document) London: Department of Health

56 J. of Practice Teaching \& Learning 9(2) 2009, pp.33-56. DOI: 10.1921/146066910X518094. @ wEbb 